\title{
Implementasi Resource Traffic Management System pada Sistem Operasi Android Dan iOS
}

\author{
Ida Ayu Gde Suwiprabayanti Putra \\ Program Studi Sistem Informasi, STMIK STIKOM Bali \\ Jalan Raya Puputan No.86 Renon Denpasar - Bali, Telp. 0361-244445 \\ e-mail: suwiprabayanti@gmail.com
}

\begin{abstract}
Abstrak
Masalah sumber daya merupakan obyek dan subyek yang sangat penting dalam mengelola suatu project. Dalam pengalokasian sumber daya tenaga kerja sering kali menimbulkan konflik karena kurangnya ketersediaan kebutuhan tenaga kerja pada suatu waktu. Untuk menyelenggarakan project, salah satu sumber daya yang menjadi faktor penentu keberhasilan adalah tenaga kerja. Faktor lain yang tidak kalah penting adalah media komunikasi antar anggota dalam project. Berdasarkan permasalahan tersebut maka dibangunlah aplikasi Reffic MS (Resource Traffic Management System) yang merupakan aplikasi mobile dengan menggunakan platform Android dan iOS sehingga bermanfaat untuk mengatur pembagian sumber daya project. Sistem dibangun dengan menggunakan metode SDLC. Analisis kebutuhan dilakukan terlebih dahulu secara fungsional dan non fungsional. Selanjutnya dilakukan perancangan sistem berdasarkan kebutuhan, dan implementasi pada framework mobile platform Android native menggunakan Android Studio dan mobile platform iOS native menggunakan XCode. Terakhir, dilakukan uji coba terhadap sistem untuk melihat apakah semua menu aplikasi sudah berjalan dengan baik.
\end{abstract}

Kata kunci: Mobile Phone Android, Mobile Phone iOS, Manajemen Sumber Daya.

\begin{abstract}
Resource problems are objects and subjects that are very important in managing a project. In allocating labor resources often creates conflict because of the lack of availability of labor needs at a time. To organize a project, one of the resources that becomes a determining factor for success is labor. Another important factor is the communication media between members in the project. Based on this problem, the Reffic MS (Resource Traffic Management System) application which is a mobile application using the Android and iOS platforms is built so that it is useful to manage the distribution of project resources. The system is built using the SDLC method. Needs analysis is carried out first functionally and non-functionally. Furthermore, system design is based on needs, and the implementation of the Android mobile platform framework natively uses the Android Studio and the iOS mobile platform natively using XCode. Finally, a trial is carried out on the system to see whether all application menus are running properly.
\end{abstract}

Keywords: Mobile Phone Android, Mobile Phone iOS, Resource Management.

\section{Pendahuluan}

Masalah sumber daya merupakan obyek dan subyek yang sangat penting dalam mengelola suatu project. Pengambilan keputusan dalam suatu project harus memperhatikan semua faktor yang ada. Dalam menentukan alokasi sumber daya project, beberapa aspek yang perlu diperhatikan dan dipertimbangkan adalah jumlah sumber daya yang tersedia dengan kebutuhan maksimal project, kondisi anggaran untuk membayar sumber daya yang akan digunakan, produktivitas sumber daya, kemampuan dan kapasitas sumber daya yang akan digunakan, efektivitas dan efisiensi sumber daya yang akan digunakan. Dalam pengalokasian sumber daya tenaga kerja sering kali menimbulkan konflik karena kurangnya ketersediaan kebutuhan tenaga kerja pada suatu waktu. Hubungan pekerjaan antar aktivitas pada suatu project akan mempengaruhi antar satu dengan lainnya. Jalur kritis yang penentuannya masih berdasarkan durasi pada project akan sangat erat kaitannya terhadap pengaruh alokasi sumber daya [1]. Untuk menyelenggarakan project, salah satu sumber daya yang menjadi faktor penentu keberhasilan adalah tenaga kerja [2].

Faktor lain yang tidak kalah penting adalah media komunikasi antar anggota dalam project. Salah satu cara untuk meningkatkan kerja sama antara anggota tim adalah mendorong terselenggaranya komunikasi dan interaksi antar anggota tim, serta pembinaan yang intensif sehingga masing-masing 
anggota mengetahui peranannya dalam tim, setiap anggota merasa saling diperlukan, anggota merasakan bahwa kerja sama sebagai satu tim akan menghasilkan lebih besar daripada bekerja sendiri-sendiri secara terpisah [3]. Melalui media komunikasi, anggota tim dapat berbagi informasi dan komunikasi untuk meningkatkan kerja sama tim. Komunikasi yang terhambat dapat menyebabkan anggota project membagikan informasi atau dokumentasi secara terpisah sehingga informasi tidak tersebar secara tepat. Faktor-faktor tersebut memperlihatkan bahwa dibutuhkan suatu sistem komunikasi dan distribusi dokumentasi terpusat yang dapat mengatur sumber daya manusia agar setiap project dapat ditangani oleh sumber daya yang sesuai serta dapat menyelesaikan project berdasarkan tenggat waktu yang ditentukan.

Untuk menyelesaikan permasalahan-permasalahan tersebut, dibangunlah suatu sistem yaitu aplikasi Reffic MS (Resource Traffic Management System). Aplikasi ini merupakan aplikasi mobile yang berjalan di atas platform Android dan iOS sehingga bermanfaat untuk mengatur sumber daya internal baik secara technical maupun fungsional agar dapat dengan tepat dimasukkan ke project yang membutuhkan. Dalam pembuatan sistem, analisis kebutuhan dilakukan terlebih dahulu secara fungsional dan non fungsional. Selanjutnya dilakukan perancangan sistem berdasarkan kebutuhan, dan implementasi pada framework mobile platform Android native menggunakan Android Studio dan mobile platform iOS native menggunakan XCode. Terakhir, dilakukan uji coba terhadap sistem untuk melihat apakah semua menu aplikasi sudah berjalan dengan baik. Dengan diimplementasikannya mobile application Reffic MS ini diharapkan sumber daya merasa nyaman dan lebih percaya diri ketika dimasukkan ke dalam project karena telah disesuaikan dengan kompetensi yang dimiliki, dari sisi seorang project manager juga akan lebih terbantu dengan aplikasi ini karena aplikasi akan memberikan saran atas sumber daya yang sesuai dengan kebutuhan project yang ditangani.

\section{Metodologi Penelitian}

\subsection{State of the Art}

Terdapat beberapa penelitian sebelumnya terkait dengan manajemen sumber daya seperti penelitian dengan studi kasus PT. Smart Moving Indonesia. Penelitian ini bertujuan untuk membantu manajemen perusahaan dalam mengelola SDM yang ada melalui modul-modul yang disediakan dan diperlukan oleh perusahaan. Selain itu karena SDM yang ada harus terus di perbaharui mengikuti perkembangan zaman dalam segala aspek termasuk teknologi informasi, sebab kalau tidak, kemampuan yang dimiliki seorang karyawan (SDM) lama-kelamaan tidak lagi dapat dipergunakan, maka aplikasi di buat berbasis web [4].

Berdasarkan hasil analisis, implementasi aplikasi Orange Human Resource Management sangat membantu dalam pengelolaan sumber daya manusia pada PT. Smart Moving Indonesia. Manajemen perusahaan dapat menggunakan aplikasi ini untuk meningkatkan kinerja karyawan yang pada akhirnya juga meningkatkan mutu perusahaan melalui modul-modul yang ada yaitu modul Admin, modul PIM (Personal Indentity Mangement), modul ESS (Employee Self Service), modul Leaves (Cuti), Modul Time, modul Report dan modul Rekrutmen. Tetapi pada aplikasi ini masih ada beberapa kebutuhan perusahaan yang tidak dapat terpenuhi. Aplikasi ini juga belum membantu dalam pengelolaan keuangan harian untuk operasional karyawan. Aplikasi ini sebagian besar membantu mencatat semua aktivitas dalam tahap perencanaan tetapi tidak ada catatan dalam tahap pelaksanaan aktivitas (personnel records), contohnya pencatatan training karyawan dan pencacatan reward yang seharusnya diberikan oleh perusahaan kepada karyawan, sehingga dapat terlihat dengan jelas karyawan yang berprestasi, yang bekerja baik atau tidak. Berdasarkan kesimpulan di atas, masih terdapat kekurangan dengan adanya kebutuhan yang tidak terjawab, oleh karena itu penulis berharap pada penulisan yang selanjutnya dapat dilakukan penelitian lanjutan yang mengukur kinerja dan peningkatan perusahaan dilihat berdasarkan laporan keuangan dan personnel records (pencatatan riwayat kerja karyawan) [4].

\subsection{Metode Penelitian}

Metode yang digunakan untuk merancang Resource Traffic Management System (Reffic MS) ini adalah System Development Life Cycle (SDLC). Dalam proses perancangannya dilakukan tahapan analisis kebutuhan, perancangan sistem, implementasi dan uji coba.

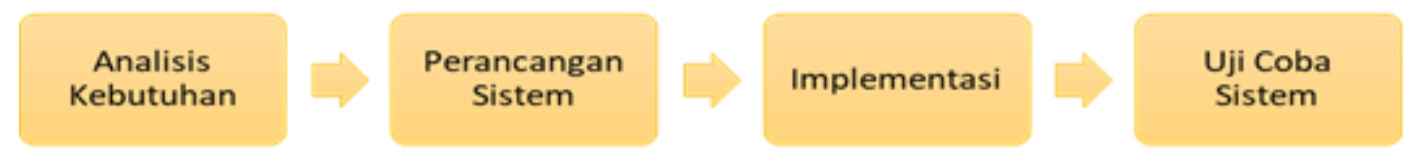

Gambar 1. Tahapan metode penelitian. 
Tahap pertama adalah analisis kebutuhan. Dilakukan analisis terhadap kebutuhan sistem secara fungsional maupun non fungsional. Kebutuhan fungsional terkait dengan jenis perangkat lunak, pengguna sistem dan jenis sistem. Sedangkan kebutuhan non fungsional terkait dengan properti perilaku yang dimiliki oleh sistem. Tahap kedua adalah perancangan sistem. Perancangan sistem dilakukan sesuai dengan kebutuhan sistem dan untuk memudahkan implementasi sistem nantinya. Tahap perancangan sistem meliputi perancangan konsep, navigasi sistem, dan rancangan antarmuka sistem. Tahap ketiga adalah implementasi sistem. Tahapan implementasi dilakukan pada platform Android dan iOS. Tahap keempat adalah uji coba sistem. Uji coba dilakukan dengan menjalankan aplikasi dan melakukan pengecekan apakah semua fungsi sudah berjalan dengan baik.

\subsection{Tinjauan Pustaka}

\subsubsection{Resource Management System}

Manajemen sumber daya manusia adalah suatu ilmu atau cara bagaimana mengatur hubungan dan peranan sumber daya (tenaga kerja) yang dimiliki oleh individu secara efisien dan efektif serta dapat digunakan secara maksimal sehingga tercapai tujuan ( $g$ oal) bersama perusahaan, karyawan dan masyarakat menjadi maksimal. Menurut Gary Dessler, manajemen sumber daya manusia adalah kebijakan dan praktik yang dibutuhkan seseorang untuk menjalankan aspek "orang” atau sumber daya manusia dari posisi seorang manajemen, meliputi perekrutan, penyaringan, pelatihan, pengimbalan dan penilaian. Sedangkan menurut Melayu Hasibuan, manajemen sumber daya manusia adalah ilmu dan seni yang mengatur hubungan dan peranan tenaga kerja agar efektif dan efisien membantu terwujudnya tujuan perusahaan, karyawan dan masyarakat. Jadi dapat ditarik kesimpulan bahwa manajemen sumber daya manusia adalah kegiatan mengatur dan mengelola sumber daya manusia yang ada di dalam suatu perusahaan agar tercapai tujuan perusahaan [5].

\subsubsection{Mobile Platform Android}

Android pertama kali dikembangkan oleh sebuah perusahaan bernama Android Inc. Kemudian pada tahun 2005, Google mengakuisisi perusahaan ini. Pada tahun 2007, Google dan beberapa perusahaan yang tergabung dalam Open Handset Alliance (Intel, Nvidia, Texas Instrument) mengembangkan sistem operasi Android dan resmi menjadi open source. Android adalah sistem operasi untuk telepon seluler yang berbasis Linux. Android menyediakan platform yang bersifat open source bagi para pengembang untuk menciptakan sebuah aplikasi. Telepon pertama yang memakai sistem operasi Android adalah HTC Dream, yang dirilis pada 22 Oktober 2008. Arsitektur Android dapat dijelaskan sebagai berikut [6]:

a. Application dan Widgets

Application dan Widgets ini adalah layer dimana kita berhubungan dengan aplikasi saja, dimana biasanya kita download aplikasi kemudian kita lakukan instalasi dan jalankan aplikasi tersebut. Di layer terdapat aplikasi inti termasuk klien email, program SMS, kalender, peta, browser, kontak, dan lain-lain. Hampir semua aplikasi ditulis menggunakan bahasa pemrograman Java.

b. Application Frameworks

Android adalah "Open Development Platform" yaitu Android menawarkan kepada pengembang atau memberi kemampuan kepada pengembang untuk membangun aplikasi yang bagus dan inovatif. Pengembang bebas untuk mengakses perangkat keras, akses informasi sumber daya, menjalankan service background, mengatur alarm, dan menambah status notifications, dan sebagainya. Pengembang memiliki akses penuh menuju API framework seperti yang dilakukan oleh aplikasi kategori inti. Arsitektur aplikasi dirancang supaya kita dengan mudah dapat menggunakan kembali komponen yang sudah digunakan (reuse). Sehingga bisa kita simpulkan Application Frameworks ini adalah layer dimana para pembuat aplikasi melakukan pengembangan/pembuatan aplikasi yang akan dijalankan di sistem operasi Android, karena pada layer inilah aplikasi dapat dirancang dan dibuat, seperti content providers yang berupa SMS dan panggilan telepon. (Nazruddin, 2011). Komponenkomponen yang termasuk di dalam Application Frameworks adalah Views, Content Provider, Resource Manager, Notification Manager, Activity Manager.

c. Libraries

Libraries ini adalah layer dimana fitur-fitur Android berada, biasanya para pembuat aplikasi mengakses libraries untuk menjalankan aplikasinya. Berjalan di atas Kernel, layer ini meliputi berbagai library $\mathrm{C} / \mathrm{C}++$ inti seperti Libc SSL, serta 7 library berikut Libraries media untuk pemutaran media audio dan video. Libraries untuk manajemen tampilan. Libraries Graphics mencakup SGL dan OpenGL untuk grafis 2D dan 3D. Libraries SQLite untuk 
dukungan database. Libraries SSL dan WebKit terintegrasi dengan web browser dan security. Libraries LiveWebcore mencakup modern web browser dengan engine embedded web view. Libraries 3D yang mencakup implementasi OpenGL ES1.0 API's.

d. Android Run Time Layer

Android Run Time Layer yang membuat aplikasi Android dapat dijalankan dimana dalam prosesnya menggunakan Implementasi Linux. Dalvik Virtual Machine (DVM) merupakan mesin yang membentuk dasar kerangka aplikasi Android. Di dalam Android Run Time dibagi menjadi dua bagian yaitu Core Libraries dan Dalvik Virtual Machine.

e. Linux Kernel

Linux Kernel adalah layer dimana inti dari sistem operasi Android itu berada. Berisi file-file sistem yang mengatur sistem processing, memory, resource, drivers, dan sistem-sistem operasi Android lainnya. Linux Kernel yang digunakan Android adalah Linux Kernel release 2.6 .

\subsubsection{Mobile Platform iOS}

iOS adalah sistem operasi perangkat bergerak yang dikembangkan dan didistribusikan oleh Apple Inc. Sistem operasi ini pertama diluncurkan tahun 2007 untuk iPhone dan iPod Touch, dan telah dikembangkan untuk mendukung perangkat Apple lainnya seperti iPad dan Apple TV. User interface dari iOS menggunakan dasar konsep dari direct manipulation, menggunakan multi-touch gestures. Kontrol interface-nya terdiri dari sliders, switches dan buttons. Interaksi dengan iOS dapat dilakukan dengan swipe, tap, pinch dan reverse pinch. Ada pula accelerometer yang digunakan untuk mendeteksi arah pergerakan dari device [7].

\section{Hasil dan Analisis}

\subsection{Kebutuhan Sistem}

\subsubsection{Kebutuhan Fungsional}

1. Sistem harus mampu melakukan perbedaan login antara Project Owner dan Team Project.

2. Sistem harus mampu menampilkan project-project yang sedang dikerjakan dan requirement dari project.

3. Sistem harus mampu menampilkan list sumber daya yang tersedia untuk dimasukkan ke dalam suatu project.

4. Sistem harus mampu menampilkan tanda jika sumber daya telah mencapai batas maksimal mengerjakan project.

5. Sistem harus mampu merekam profil dan kompetensi yang dimiliki oleh masing-masing sumber daya.

6. Sistem harus mampu menangani live chat anggota untuk masing-masing project.

\subsubsection{Kebutuhan Non Fungsional}

1. Operasional

a. Mobile Platform Android Minimum Version 7.0.0

b. Mobile Platform iOS Minimum Version 4.5.4

c. Minimum Space Storage $2.5 \mathrm{MB}$

2. Keamanan

a. Sistem menggunakan login akses user dengan password terenkripsi dengan metode md5.

3. Informasi

a. Aplikasi dengan role sebagai Project Owner berfungsi untuk melakukan management project dan alokasi sumber daya.

b. Aplikasi dengan role Resource berfungsi untuk melakukan update kompetensi.

\subsection{Perancangan Sistem}

\subsubsection{Platform Android} berikut :

Untuk membangun aplikasi ini di atas platform Android, digunakan beberapa environment sebagai

1. JDK 1.8.0_171, JDK adalah software development environment yang berguna untuk mengembangkan aplikasi berbasis Java.

2. Android Studio, merupakan IDE yang digunakan untuk membangun suatu aplikasi berbasis mobile pada platform Android. 
3. Android SDK, merupakan Software development Kit, yaitu tool yang dibutuhkan untuk pengembangan aplikasi berbasis Android yang terdiri dari debugger, libraries, handset serta emulator.

Aplikasi ini dibangun diatas 3 layer diantaranya:

- Layer UI (User Interface) yang berbasis Android dibangun dengan menggunakan Android Studio.

- Layer Background Proses REST API (REpresentational State Transfer) merupakan standar arsitektur komunikasi atau interface, untuk membangun background proses dari aplikasi ini, menggunakan framework C\# .net, dengan tool Visual Studio Community Version 7.5.3.7.

- Layer Database menggunakan database MySql 5, semua table master, parameter dan transaksi dibangun pada database ini.

\subsubsection{Platform iOS} berikut:

Untuk membangun aplikasi ini di atas platform iOS digunakan beberapa environment sebagai

- Mac OS untuk dapat mengerjakan aplikasi iOS dibutuhkan operating system Machintos, pada aplikasi ini dibangun di atas Mac OS versi High Sierra 10.13.6

- XCode, merupakan IDE (Integrated Development Environtment) pengembangan berbagai produk Apple. Mulai dari iOS, OS X, watchOS, dan tvOS, untuk membangun aplikasi ini menggunakan XCode version 9.4.1

Aplikasi ini dibangun di atas 3 layer diantaranya :

- Layer UI (User Interface) yang berbasis iOS dibangun dengan menggunakan XCode.

- Layer Background Proses REST api (REpresentational State Transfer) merupakan standar arsitektur komunikasi atau interface, untuk membangun background proses dari aplikasi ini, menggunakan framework C\# .net, dengan tool Visual Studio Community Version 7.5.3.7

- Layer Database menggunakan database MySql 5, semua table master, parameter dan transaksi dibangun pada database ini.

\subsubsection{Aplikasi Pendukung}

Sebagai aplikasi pendukung dari kedua aplikasi ini digunakan tool yaitu Firebase. Firebase merupakan BaaS (Backend as a Service) yang saat ini dimiliki oleh Google. Firebase ini merupakan solusi yang ditawarkan oleh Google untuk mempermudah pekerjaan Mobile Apps Developer. Untuk aplikasi ini memanfaatkan Firebase sebagai realtime Cloud Messanging dan Notification, baik untuk aplikasi yang berjalan pada platform Android maupun iOS.

\subsubsection{Hosting}

Hosting digunakan untuk aplikasi ini baik yang berjalan pada platform Android ataupun iOS adalah Windows webhosting sebagai hosting untuk API/background proses hosting.

\subsection{Implementasi}

Sistem Reffic MS diimplementasikan pada kedua platform yaitu Android dan iOS sesuai dengan perancangan sistem yang telah dilakukan.

\subsubsection{Tampilan Home Aplikasi}
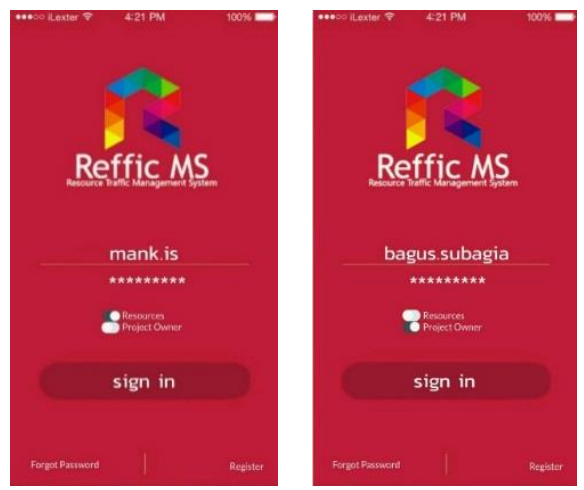

Gambar 2. Home aplikasi. 
Aplikasi Reffic MS memiliki 2 role user login yaitu role sebagai Project Owner (merupakan PIC yang bertanggung jawab pada project / Project Manager) serta role sebagai Resources (Member atau Team project baik itu sisi Technical dan Fungsional).

\subsubsection{Tampilan List Project}

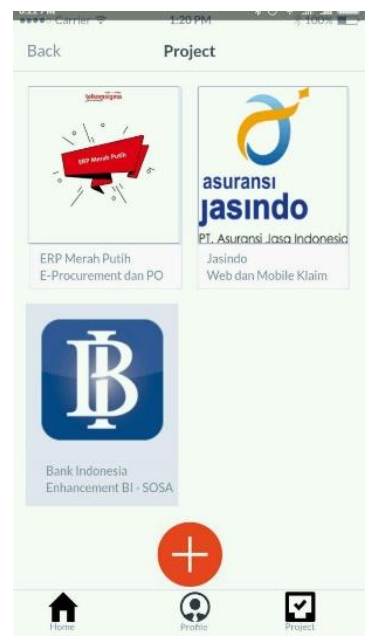

Gambar 3. List project.

Setelah berhasil melakukan login sebagai project owner maka aplikasi akan memunculkan list dari project yang sedang di tangani oleh project owner (project manager), pada page ini dapat dilihat juga detail dan deskripsi dari project-project tersebut dengan cara memilih salah satu project.

\subsubsection{Tampilan Project Register}

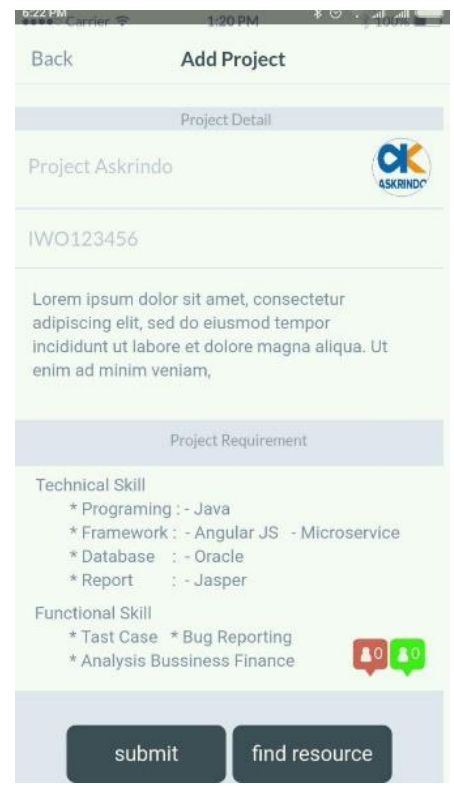

Gambar 4. Project register.

Pada halaman ini, project owner dapat memberikan deskripsi singkat tentang project, dan requirement dari sumber daya yang dibutuhkan dari project tersebut baik di sisi teknikal dan sisi fungsional, pada halaman ini juga disediakan fitur find resource, jadi aplikasi akan membantu project owner untuk menemukan sumber daya yang memiliki kompetensi sesuai dengan kebutuhan project yang sedang ditangani. 


\subsubsection{Tampilan Resource Suggest}

Pada halaman ini project owner dapat mengundang sumber daya yang sesuai, dimana sumber daya yang dapat diundang hanya sumber daya yang menampilkan lampu berwarna hijau (belum di book di project mana pun) dan kuning (sedang mengerjakan sebuah project atau maksimal 2 project), jika sumber daya tersebut mengerjakan 3 project maka tidak dapat di-invite lagi ke project yang baru, sampai salah satu project yang sedang ditanganinya selesai.

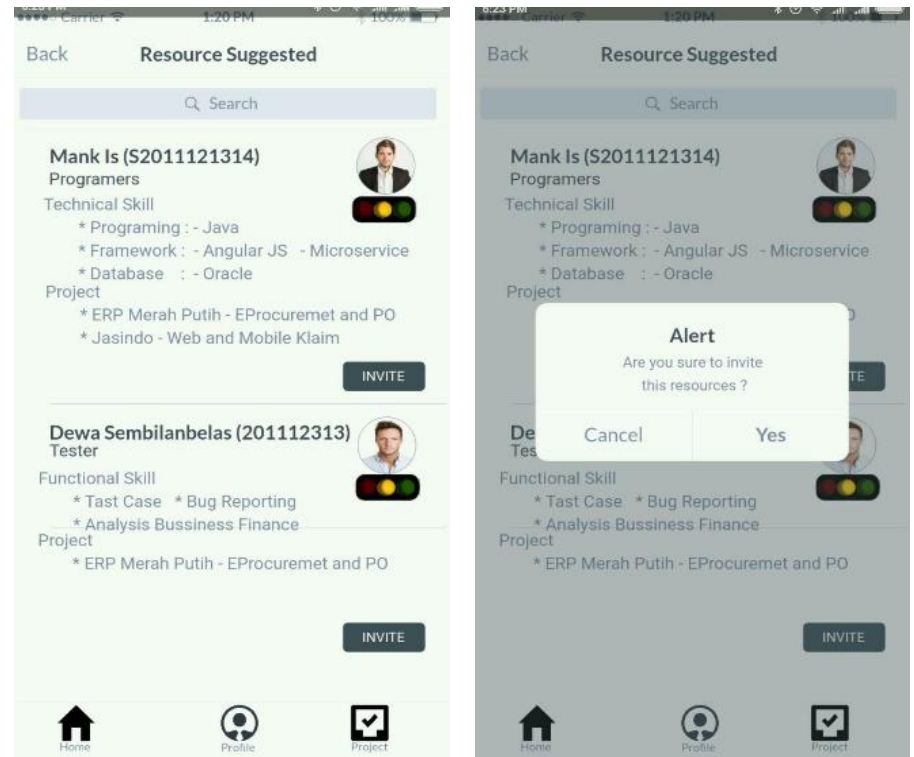

Gambar 5. Resource suggest.

\subsubsection{Tampilan Submit Project}
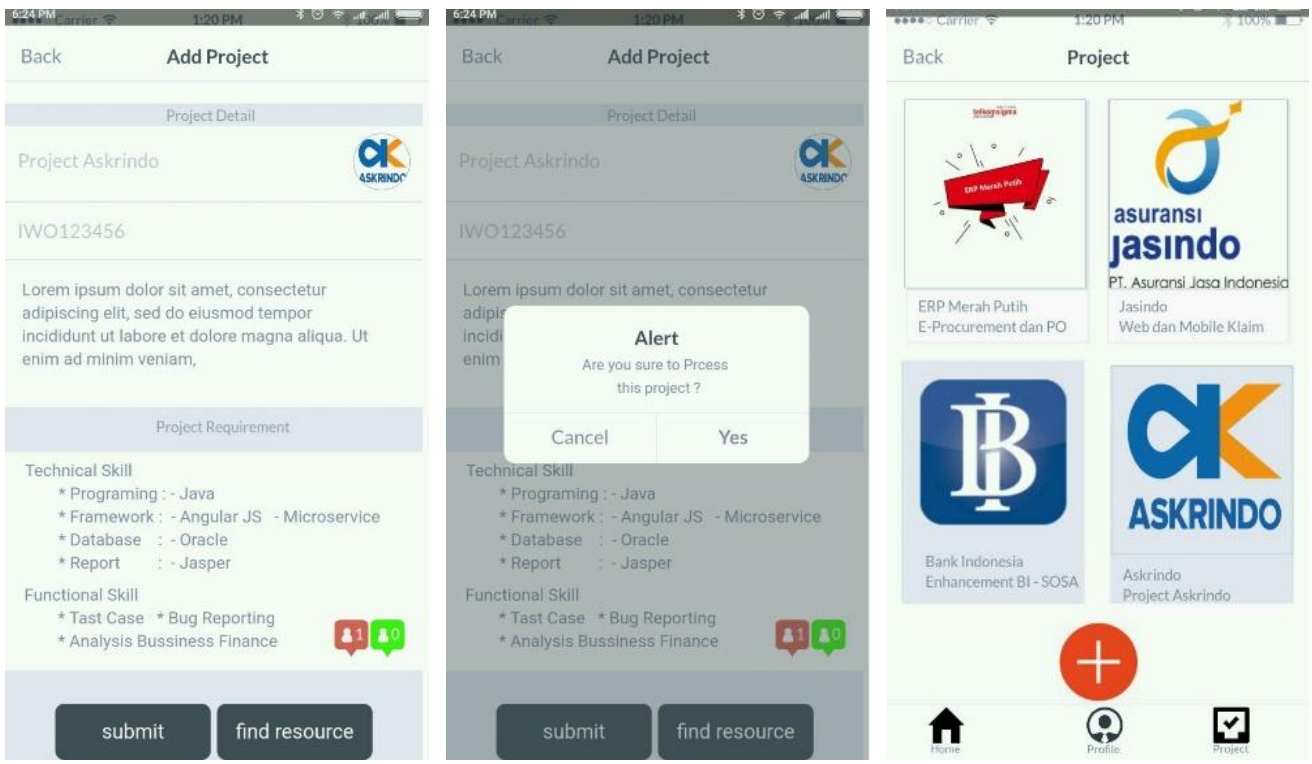

Gambar 6. Submit project.

Ketika sumber daya telah terpilih maka akan muncul pada bubble warna merah menampilkan jumlah sumber daya yang telah di invite, jika sudah di terima oleh sumber daya tersebut maka akan tampil jumlah sumber daya yang sudah menerima di bubble berwarna hijau. Project dapat di submit dan jika dibutuhkan adanya perubahan dan invite sumber daya lagi maka akan dapat di update kembali. 


\subsubsection{Tampilan Login Role Resource}

Ketika user melakukan login dengan role resources, maka pada halaman utamanya user akan ditampilkan project yang sedang ditangani, user dapat melihat detail project, melihat tim yang menangani project tersebut dan melakukan interaksi dengan tim melalui live chat sehingga user dapat melakukan interaksi ke sesama member project tersebut.
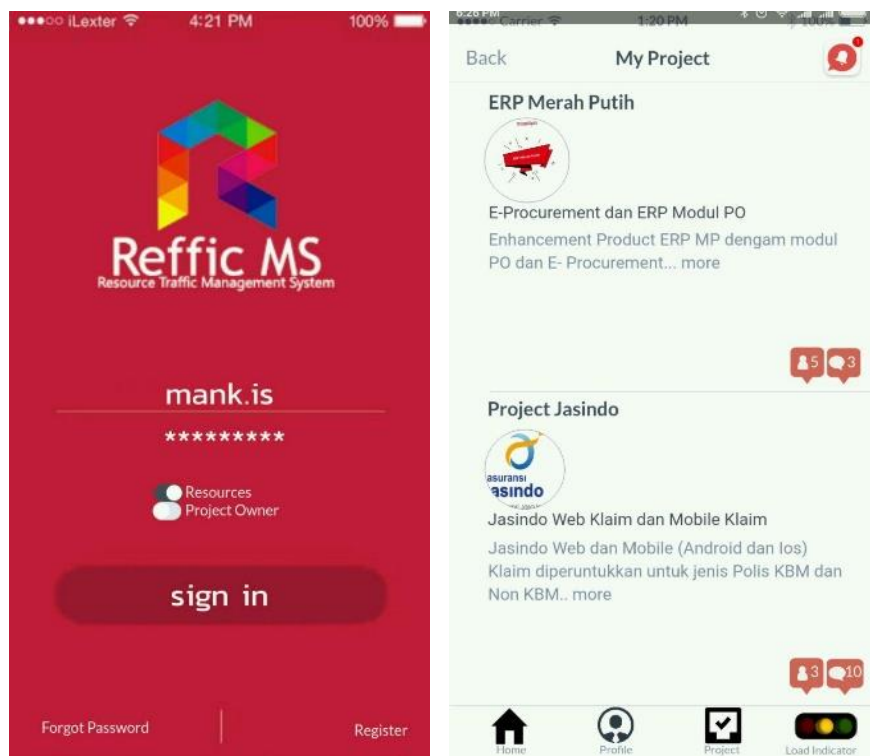

Gambar 7. Login role resource (1).

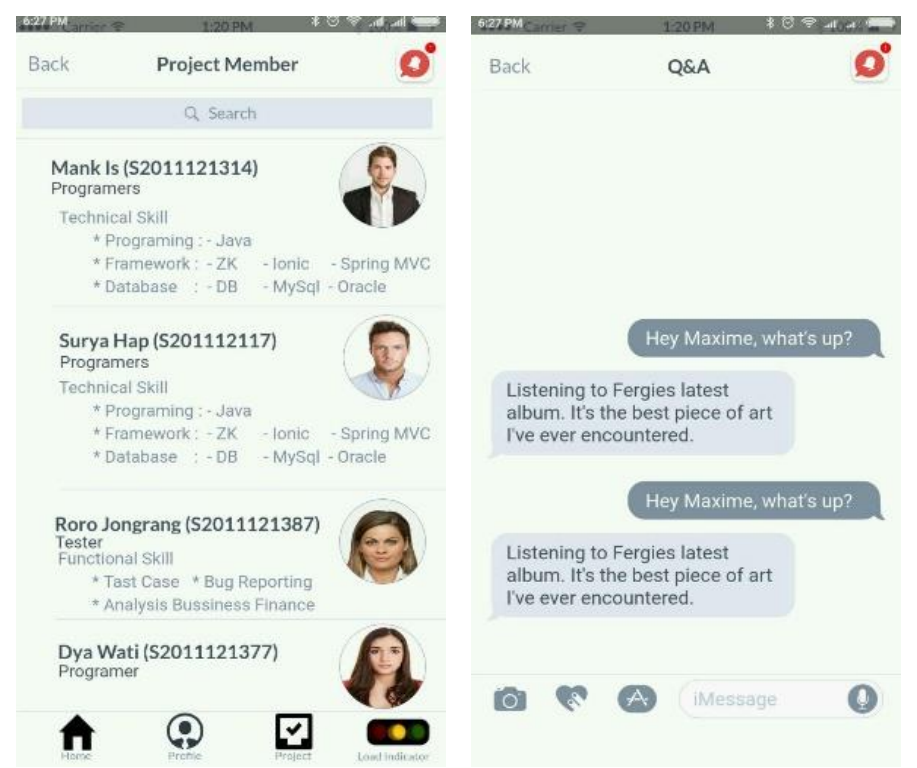

Gambar 8. Login role resource (2).

\subsubsection{Tampilan Update Profile dan Kompetensi}

User aplikasi ini baik project owner ataupun resources dapat melakukan update profil dan kompetensi sehingga perusahaan dapat mengetahui update data dan kompetensi dari karyawannya sehingga sangat bermanfaat untuk project lainnya, aplikasi akan menotifikasi secara berkala untuk mengingatkan user untuk selalu melakukan update profil dan kompetensi sehingga kualitas data profile dan kompetensi ini valid. 


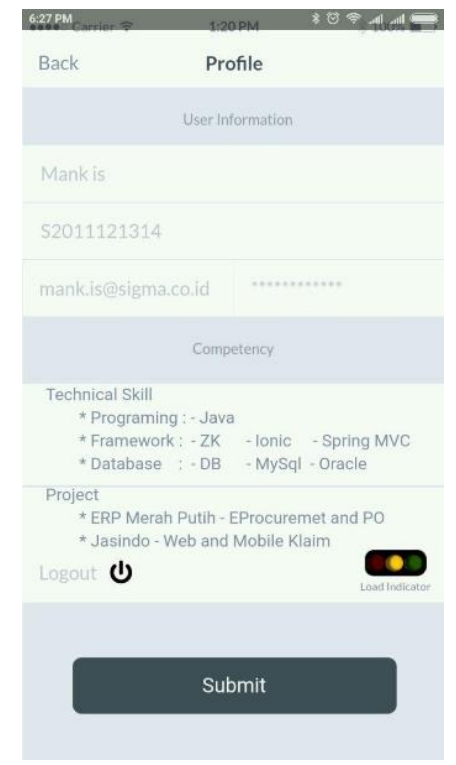

Gambar 9. Update profile dan kompetensi.

\subsection{Uji Coba Sistem}

Uji coba dilakukan untuk mengetahui kekurangan pada aplikasi seperti tampilan sistem yang salah, tombol yang tidak bekerja, tidak memasuki menu aplikasi yang seharusnya ataupun kelemahan lainnya pada aplikasi. Uji coba dilakukan langsung dengan menggunakan 2 ponsel yaitu ponsel yang menggunakan Android dan ponsel yang menggunakan iOS. Uji coba dilakukan dengan menjalankan keseluruhan menu aplikasi pada ponsel. Hasil uji coba terlihat pada Tabel 1, dari hasil uji coba didapatkan bahwa semua menu sudah berjalan sesuai dengan yang diharapkan.

Tabel 1. Uji coba sistem.

\begin{tabular}{ll}
\hline \multicolumn{1}{c}{ Menu } & Ponsel Android dan iOS \\
\hline Home & Sesuai \\
\hline List Project & Sesuai \\
\hline Project Register & Sesuai \\
\hline Resource Suggest & Sesuai \\
\hline Submit Project & Sesuai \\
\hline Role Resources & Sesuai \\
\hline Update Profil dan Kompetensi & Sesuai \\
\hline
\end{tabular}

\section{Kesimpulan}

Kesimpulan yang didapatkan dari penelitian ini adalah :

1. Resource Traffic Management System dapat mengatur internal resources baik teknikal maupun fungsional agar dapat dengan tepat di-assign ke project yang membutuhkan dengan menyesuaikan pada load dan kompetensi masing-masing anggota

2. Resource Traffic Management System meminimalkan risiko pada durasi dan kualitas project dengan melakukan penentuan project member dan pengaturan waktu.

3. Resource Traffic Management System dapat diimplementasikan dengan baik pada dua Platform yaitu Platform Android dan Platform iOS.

\section{Daftar Pustaka}

[1] A. Husen. Manajemen Proyek Perencanaan, Penjadwalan \& Pengendalian Proyek. Yogyakarta: C.V Andi Offset. 2009.

[2] N. M. Jaya and A. A. D. P. Dewi, "Analisa Penjadwalan Proyek Menggunakan Ranked Positional Weight Method dan Precedence Diagram Method (Studi Kasus:Proyek Pembangunan Pasar Mumbul di Kabupaten Buleleng)," J. Ilm. Tek. Sipil, vol. 11, no. 2, pp. 100-108, 2017.

[3] S. Iman. Manajemen Proyek Konstruksi. Jakarta: Erlangga. 1995.

[4] J. Lini, Esther. "Analisis Implementasi Aplikasi Orange Human Resource Management. (Studi Kasus PT. Smart Moving Indonesia)," E-Journal Komputer, pp. 1-10. 2012. 
[5] N. Purwandari, R. W. P. Pamungkas, "Implementasi Modul Human Resource Management menggunakan Open Enterprise Resources Planing pada Perusahaan Profit Wilis," Kalbiscentia: Jurnal Sains dan Teknologi, vol. 3, no. 2, pp. 1-13. 2016.

[6] R. P. Warouw, A. A. E. Sinsuw, X. B. N. Najoan, "Perancangan Aplikasi Voter Berbasis Android Studi Kasus Pemilihan Ketua Himpunan Mahasiswa Jurusan Teknik Elektro Universitas Sam Ratulangi Manado,” Jurnal Teknik Elektro dan Komputer, vol 3, no.5 pp. 10-18. 2014.

[7] K. A. F. Amiton, KM. S. Haryana, R. N. Ibhahim, "Pengembangan Aplikasi Belajar Menulis Alfabet dan Angka untuk Perangkat Mobile berbasis Android dan IOS menggunakan Framework COCOS2," Jurnal Computech \& Bisnis, vol. 7, no. 1, pp. 1-12. 2013. 